\title{
Family-Friendly Human Resource Practice, Organizational Commitment, and Job Performance among Employees: The Mediating Role of Workplace Spirituality
}

\author{
Jianglin Ke, Xiuting Deng* \\ School of Government, Beijing Normal University, Beijing, China \\ Email: kejinglin@126.com, *dxiuting@126.com
}

How to cite this paper: Ke, J.L. and Deng, X.T. (2018) Family-Friendly Human Resource Practice, Organizational Commitment, and Job Performance among Employees: The Mediating Role of Workplace Spirituality. Journal of Human Resource and Sustainability Studies, 6, 81-91. https://doi.org/10.4236/jhrss.2018.61028

Received: March 2, 2018

Accepted: March 23, 2018

Published: March 26, 2018

Copyright $\odot 2018$ by authors and Scientific Research Publishing Inc. This work is licensed under the Creative Commons Attribution International License (CC BY 4.0).

http://creativecommons.org/licenses/by/4.0/

\begin{abstract}
The aim of this article is to examine the effect of family-friendly human resource practice on employees' organizational commitment and job performance, and the role of workplace spirituality fit within the prior relationship. To this end, this research collects 347 samples data, and conducts a hierarchical regression analysis. The results show that family-friendly human resource practice has a significant positive effect on the organizational commitment and job performance of employees, whilst workplace spirituality plays a partial intermediary role in the relationship. This research suggests that organizations should pay attention to the implementation of family-friendly human resource practice in order to improve organizational commitment and job performance of employees, thus enhancing the organization's competitive advantages.
\end{abstract}

\section{Keywords}

Family-Friendly Human Resource Practice, Organizational Commitment, Job Performance, Workplace Spirituality

\section{Introduction}

With the continued intensification of global competition and development of information technology, nowadays employers seldom implement the traditional nine-to-five schedule, and it has become increasingly arduous for employees to draw physical and psychological boundaries between their work and family life [1]. Therefore, work-family conflict becomes a prominent issue for the career people, which could cause a negative impact on individuals, families and organ- 
izations [2]. In the past few decades, many scholars have conducted research on work-family conflict from different disciplinary perspectives, such as psychology, sociology, organizational behavior and management. They have collected sufficient evidence to prove that work-family conflict is a universal phenomenon and may result in a variety of negative outcomes including risks to physical and mental health, poor job performance, low job involvement, low job satisfaction and high employee turnover rates [3] [4]. According to this, prevention of work-family conflicts should consider a priority for organizations. In Western countries, various family-friendly work practices have been introduced to help employees achieve a good balance between their work and family lives [2]. It can help employees fulfill their family responsibilities and improve their working conditions at the same time by providing flexible work hours, telecommuting, medical aid, paid vacation, onsite or nearby childcare facilities, counseling and employee assistance programs and so on [5]. So it is an important way for employers to attract and retain talented employees.

Meanwhile, in an increasingly competitive world, employees' organizational commitment and job performance have become important components of human resource management. Organization commitment is a psychological link between employees and their organizations, which makes it less likely for employees to voluntarily leave the organization [6]. Job performance is typically conceptualized as "actions and behaviors that are under the control of the individual that contribute to the goals of the organization" [7]. Both are all highly related to the development of an organization. So the improvement of employee's organizational commitment and job performance is always a priority for organizations. Up to now, the relevant empirical study aimed at the influence of family-friendly human resource practice on organizational commitment and job performance is limited. So studies on the influence have an important practical significance to the development of organizations and employees, and should be encouraged to offset the limitation of the previous research.

In addition to the direct relationship mentioned above, the effect of workplace-spirituality as an intermediary role on organizational commitment and job performance is also worthy of further in-depth study. Workplace spirituality can be defined as the "recognition that employees have an inner life which nourishes and is nourished by meaningful work taking place in the context of a community" [8], which includes three dimensions: meaningful at work, community and alignment with organizational values [9]. According to the past research, workplace spirituality can promote the staff s job involvement [10], job satisfaction, organizational commitment [11], and job performance [12]. Family-friendly human resource practice tries to generate a caring organizational climate, provide a spiritual experience, so as to compatibility employees' goals to organizations' goals and strengthen workplace spirituality. Moreover, based on Social Exchange Theory, when employees feel cared for by their organizations, they should have a higher level of workplace spirituality, and in return they 
would improve their organizational commitment and job performance.

In China, the significance of familial values and bonds are heavily accentuated. Thus, it is consequently more meaningful to examine the influence of family-friendly human resource practice on organizational commitment and job performance and the mediating effect of workplace spirituality among the three under Chinese cultural context. By doing this research, we may explore how to create a harmonious organization atmosphere, how to reduce work-family conflicts, how to meet the spiritual needs of human resources, and how to get competitive advantages for an organization.

\section{Literature and Hypothesis}

Family-friendly human resource practice is a human resource management model designed for organizations to help employees manage work and personal life demands [13]. Many employers have come to view family-friendly human resource practice as a way to create a supportive culture and promote workplace equality [14]. Hammer (2005) [15] introduced work-family conflicts as mediating variables to explore the impact that family-friendly programs have on job satisfaction, and the results indicated that family-friendly human resource practice can by degrees help relieve female employees of their work-family conflicts at home, balance the relationship between work and family, and promote job satisfaction. Simultaneously, with the improvement of job satisfaction, employees would enhance the organization identity, to produce a stronger organizational commitment [16], and improve job performance in return [17]. For another part, Family-friendly Human Resources Policy Research Center in Muenster University and Steinbeis-Hochschule-Berlin took 1001 companies as samples, and got a conclusion that compared with other companies, those implemented family-friendly human resource practice had a higher job productivity and enthusiasm of employees by $17 \%$, and a lower absenteeism by $16 \%$. This indicates that family-friendly human resource practice can retain employees and improve job performance in a certain degree. Moreover, according to the Personal-Organization Fit Theory and Work Adjustment Theory, organizations who provide a home-like atmosphere and pleasant working environment would meet employees' demands of family and work. Highly appropriated match of the needs of employees and the work environment system can significantly improve employees' job performance, to then bring a more positive attitude and performance results. Accordingly we propose [Figure 1].

H1 Family-friendly human resource practice can promote organization commitment of employee's.

H2 Family-friendly human resource practice can promote job performance of employees.

There are research findings that indicate the adoption of family-friendly human resource practice was positively related to organizational climate [18]. Organizational climate provides a frame of reference through which individuals 


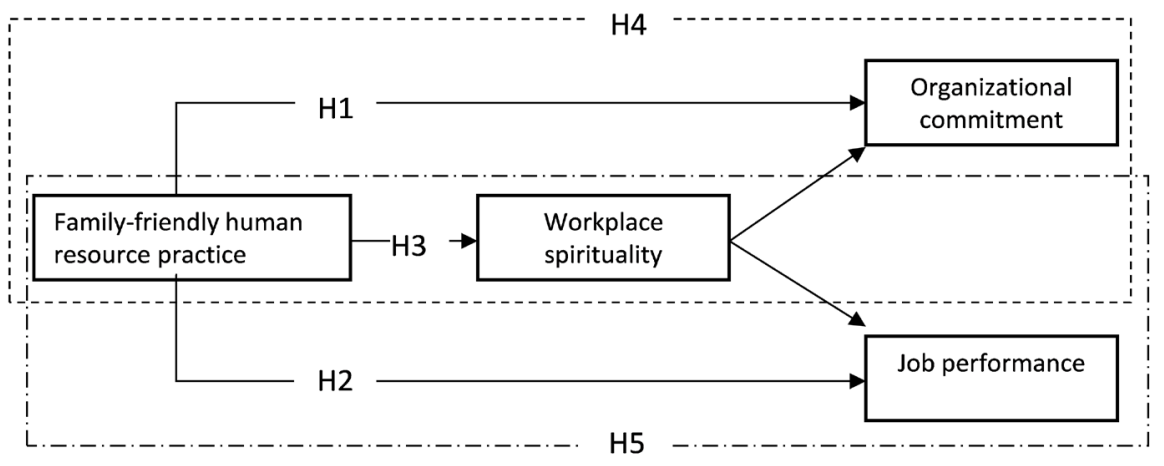

Figure 1. Research framework.

make sense of organizational life [19]. Therefore, it can facilitate workplace spirituality [20]. According to Social Identity Theory, enhanced organizational identification raises individual outcomes such as the improvement of task performance and organizational citizenship behavior [21]. By promoting the well-being and interests of staffs actively, taking in consideration of employees' family responsibilities, creating a supportive and altruistic work environment, family-friendly human resource practice provides a positive psychological experience for employees, and empowers them develop a better sense of self-identification, understand the meaning of work, and improve workplace spirituality. Accordingly we propose.

H3 Family-friendly human resource practice can promote workplace spirituality of employees.

Organization commitment and job performance could be influenced by many factors. However, no overarching research has been conducted that deals with the relationship between family-friendly human resource practice, workplace spirituality, organization commitment and job performance. Thus, we attempt to fill this gap in the research by exploring a theoretical underpinning for these linkages. When Riasudeen and Prabavathy (2011) [10] studied the relations between workplace spirituality of the employees in manufacturing and their attitude, they found that three dimensions of the workplace spirituality are all significantly positively related to job satisfaction, job involvement and job commitment. Researchers found there was a positive relationship between job satisfaction and job performance in a survey of 335 respondents that work in middle level of banking sector. On the basis of intrinsic motivation theory, workplace spirituality will have a positive effect on individuals' attitude and behavior. As a spiritual experience, workplace spirituality will meet the psychological needs of employees, which encourages more behavior beneficial to the organizations. If, as expected, family-friendly human resource practice positively influences workplace spirituality, and workplace spirituality influences organizational commitment and job performance. Workplace Spirituality, then in turn mediates the relationship between family-friendly human resource practice and organizational commitment or job performance. Accordingly we propose. 
H4 The relationship between family-friendly human resource practice and employees' organizational commitment will be mediated by workplace spirituality.

H5 The relationship between family-friendly human resource practice and employees' job performance will be mediated by workplace spirituality.

\section{Method}

\subsection{Sample}

The data used here were collected from a self-reported questionnaire for convenient sampling. The sample for the study was drawn from the on-the-job master's degree programs from Beijing Normal University and the employee groups in Beijing. People from the government, the institutions, or the enterprises are included in the sample. So it can, to some extent, represent the working staff of Beijing. Out of the total 420 questionnaires distributed, 380 copies were returned and 347 were valid. The rate of recovery was $90.5 \%$. The effective rate of recovery is $82.6 \%$. Invalid samples included those who didn't fill all the questions or fill the questions casually and also included those who have work less than half a year. Of the 347 employees analyzed, $48.4 \%$ of the respondents were men $(\mathrm{N}=$ $168)$ and $51.6 \%$ were women $(\mathrm{N}=179)$. In terms of education, the lowest degree is senior middle school and under, and highest degree is doctor. The senior middle school and under accounted for $4 \%$, associate degree accounted for $12.7 \%$, the bachelor accounted for $27.4 \%$, and the master accounted for $55.9 \%$. As for employees' relationship status, $32.6 \%$ were married and $67.4 \%$ had never married, or were divorced, or separated. In term of children, $32.9 \%$ of participates had babies.

\subsection{Measuring}

Except for the control variables, all the variables used a six-point Likert-type scale ( 1 = "strongly disagree"; 6 = "strongly agree") to respond to the items in the following measures:

Family-friendly human resource practice. Family-friendly human resource practice was measured by using the questionnaire developed by Luan Minna (2008) [22] with 19 questions including two dimensions: flexibility program and family-care program. The former has 6 questions, and the latter has 13 questions. The overall alpha is 0.96 .

Workplace spirituality. This variable is measured by a 21 -item scale developed Milliman (2003) [9]. The scale tries to capture various aspects of employees' perceptions about their feelings, including meaningful work, sense of community and alignment of values. The overall alpha was 0.93 .

Organizational commitment. Organizational commitment in the present study was measured from the organizational commitment scale developed by Meyer and Allen (1998) [23]. The scale has 18 questions, including three dimensions: affection commitment (AC), continued commitment (CC) and normative 
commitment (NC). Every dimension has 6 questions. The overall alpha is 0.81 .

Job performance. This variable is measured by the scale from Williams, L. J., \& Anderson, S. E. (1991) [24]. It includes a total of 22 items, including two dimensions of task performance and contextual performance. The overall alpha was 0.81 .

Control variables. Different gender, whether to form their own families, and whether there are children will lead to different levels of individual attention to the family. Besides, people with different qualifications may differ in their spiritual requirements. So gender, marriage, child and education were used as control variables in all of the analyses. Specifically, gender: $1=$ male, $2=$ female; marriage: 1 = married, 2 = unmarried, 3 = divorced; child: $1=$ have child, $2=$ have no child; education: 1 = senior middle school and under, 2 = associate degree, 3 = bachelor, $4=$ master, $5=$ doctor.

\subsection{Common Method Biases Test}

In order to reduce the common method biases, the questionnaire instruction states that it is an anonymous survey and there are no right or wrong answers, and we ensure that the results would not reflect any personal information. The purpose is to enable participants to complete it honestly and not to be influenced by questions throughout the entire process. In addition, we use the Harman single factor test to verify the extent of common method biases of each research variable. The results show that the single factor can only explain $16.89 \%$ of the four subjective variables' variance, indicating there was not significant common method bias in the measurement.

\section{Results}

\subsection{Correlation Analysis}

Means, standard deviations, and correlations among variables are shown in Table 1. The mean value of Family-friendly human resource practice was 3.497(on a six-point scale), suggesting that these practices are not widely adopted among our sample firms. According to the variable correlation, family-friendly human resource practice can promote employee's workplace spirituality $(\mathrm{r}=0.226, \mathrm{P}<$ $0.01)$, organizational commitment $(\mathrm{r}=0.858, \mathrm{P}<0.01)$ and job performance $(\mathrm{r}=$ $0.309, \mathrm{P}<0.01)$. These results support $\mathrm{H} 1, \mathrm{H} 2$ and H3. Meanwhile, workplace spirituality also has a significant positive effect on organizational commitment ( $\mathrm{r}$ $=0.268, \mathrm{P}<0.01)$ and job performance $(\mathrm{r}=0.138, \mathrm{P}<0.01)$.

\subsection{The Effect of Family-Friendly Human Resource Practice on Organizational Commitment}

Models 1 - 3 in Table 2 show the influence of family-friendly human resource practice on organizational commitment. The VIF of model 1-6 is less than the critical value of 10 . The $\mathrm{D}-\mathrm{W}$ value is significant at the 0.05 level which means that the model has no serious collinearity problem, and the analysis of the model 
Table 1. Mean, standard deviation, Pearson correlation coefficient of variables.

\begin{tabular}{|c|c|c|c|c|c|c|c|c|c|}
\hline & Mean & $S D$ & 1 & 2 & 3 & 4 & 5 & 6 & 7 \\
\hline 1) Gender & 1.48 & 0.500 & & & & & & & \\
\hline 2) Marriage & 1.42 & 0.580 & 0.078 & & & & & & \\
\hline 3) Child & 1.67 & 0.470 & $0.383^{* *}$ & $-0.195^{\star *}$ & & & & & \\
\hline 4) Education & 3.49 & 0.817 & $0.113^{*}$ & $0.113^{*}$ & -0.044 & & & & \\
\hline $\begin{array}{l}\text { 5) Family-friendly human } \\
\text { resource practice }\end{array}$ & 3.497 & 1.351 & -0.005 & $0.222^{\star *}$ & -0.102 & $0.361^{\star *}$ & & & \\
\hline 6) Workplace spirituality & 3.376 & 0.922 & $-0.26^{* *}$ & $-0.164^{* *}$ & -0.098 & $0.200^{* *}$ & $0.226^{* *}$ & & \\
\hline $\begin{array}{l}\text { 7) Organizational } \\
\text { commitment }\end{array}$ & 3.509 & 1.200 & 0.050 & $0.225^{\star *}$ & -0.024 & $0.360^{* *}$ & $0.858^{* *}$ & $0.268^{* *}$ & \\
\hline 8) Job performance & 4.211 & 0.961 & $0.408^{\star *}$ & 0.021 & $0.463^{\star *}$ & $0.106^{*}$ & $0.309^{\star *}$ & $0.138^{* *}$ & $0.449^{* *}$ \\
\hline
\end{tabular}

Notes: ${ }^{*}$ Correlation is significant at the 0.01 level (2-tailed); ${ }^{\star}$ Correlation is significant at the 0.05 level (2-tailed).

Table 2. Regression analysis of family-friendly human resource practice on organizational commitment and job performance.

\begin{tabular}{|c|c|c|c|c|c|c|}
\hline & \multicolumn{3}{|c|}{ Organizational commitment } & \multicolumn{3}{|c|}{ Job performance } \\
\hline & Model 1 & Model 2 & Model 3 & Model 4 & Model 5 & Model 6 \\
\hline \multicolumn{7}{|l|}{ Control variables } \\
\hline Gender & -0.013 & 0.021 & 0.050 & $0.214^{\star * *}$ & $0.226^{\star * \star}$ & $0.271^{\star * *}$ \\
\hline Marriage & $0.204^{\star * *}$ & 0.045 & $0.065^{*}$ & 0.053 & -0.004 & 0.027 \\
\hline Child & 0.032 & $0.064^{*}$ & 0.054 & $0.403^{* * *}$ & $0.415^{\star * *}$ & $0.399^{* * *}$ \\
\hline Education & $0.256^{\star * *}$ & 0.043 & 0.053 & $0.260^{\star * \star}$ & $0.183^{\star \star *}$ & $0.199^{\star * *}$ \\
\hline \multicolumn{7}{|l|}{ Independent variable } \\
\hline Family-friendly human resource practice & & $0.843^{\star * *}$ & $0.809^{* \star *}$ & & $0.304^{\star * \star}$ & $0.252^{\star * *}$ \\
\hline \multicolumn{7}{|l|}{ Mediating variable } \\
\hline Workplace spirituality & & & $0.113^{* * *}$ & & & $0.171^{* * *}$ \\
\hline $\mathrm{R}^{2}$ & 0.115 & 0.744 & 0.755 & 0.347 & 0.429 & 0.453 \\
\hline Adjusted $\mathrm{R}^{2}$ & 0.105 & 0.740 & 0.750 & 0.339 & 0.420 & 0.443 \\
\hline $\mathrm{F}$ & 11.148 & 838.08 & 14.531 & 45.442 & 48.691 & 14.946 \\
\hline$\Delta \mathrm{R}^{2}$ & 0.115 & 0.629 & 0.10 & 0.347 & 0.082 & 0.024 \\
\hline $\mathrm{F}$ & 11.148 & 198.362 & 174.283 & 45.442 & 51.161 & 46.869 \\
\hline
\end{tabular}

Notes: ${ }^{*}, \mathrm{p}<0.05 ;{ }^{* *}, \mathrm{p}<0.01 ;{ }^{* * *}, \mathrm{p}<0.001$.

is acceptable. According to model 1, marriage status and educational background have a significant effect on organizational commitment. Model 2 shows that the $\beta$ of family-friendly human resource practice is $0.843(\mathrm{p}<0.001)$. In model 3, after introducing the variable of workplace spirituality, the $\beta$ of workplace spirituality is 0.113 ( $\mathrm{p}<0.001$ ), while the $\beta$ of family-friendly human resource practice is $0.809(\mathrm{p}<0.001)$ which indicates that family-friendly human resource practice and workplace spirituality have a positive effect on organizational commitment. Compared with model 2, $\beta$ of family-friendly human re- 
source practice is thin, but still significant. This means that workplace spirituality plays a partial intermediary role between spiritual leadership and organizational citizenship behavior.

\subsection{The Effect of Family-Friendly Human Resource Practice on Job Performance}

Models 4 - 6 in Table 2 show the effects of family-friendly human resource practice on job performance. According to model 4, gender, child status and educational background have a significant effect on job performance. In model 5 , the $\beta$ of family-friendly human resource practice is $0.304(\mathrm{p}<0.001)$ which means that the practice has a significant positive effect on job performance of employees. Model 6 shows that after introducing the variable of workplace spirituality, the $\beta$ of family-friendly human resource practice reduces to 0.252 ( $\mathrm{p}<$ $0.001)$, but the $\beta$ of workplace spirituality is $0.171(\mathrm{p}<0.001)$ which has reached a significant level. This means that family-friendly human resource practice, on the one hand, has an impact on job performance through workplace spirituality, on the other hand, it can directly promote the level of job performance.

\section{Discussion}

This paper aims to examine the influence of family-friendly human resource practice on organizational commitment and job performance of employees through the intermediate effect of workplace spirituality. First, we discussed the effects family-friendly human resource practice has on organizational commitment and job performance. The results show that the correlation coefficient of family-friendly human resource practice and organizational commitment is 0.858 ( $\mathrm{p}<0.001$ ), and the correlation coefficient of family-friendly human resource practice and job performance is $0.309(\mathrm{p}<0.001)$, which indicates that family-friendly human resource practice can promote employee's organizational commitment and job performance. The result is consistent with many scholars who thought that family-friendly human resource practice can and are able to attract and retain employees [25], as well as improve employees' job attitudes and work efficiency [26]. Therefore, by creating a caring and altruistic organizational atmosphere, providing a spiritual experience, family-friendly human resource practice tries to increase the compatibility employees' goals to organizations' goals and spurs employees to improve their own job performance to return the favor to the organization.

Concurrently, this research discussed the intermediating role of workplace spirituality between family-friendly human resource practice and the attitude or behavior of employees. From Table 2, we can see that workplace spirituality plays a partial intermediary role between family-friendly human resource practice and organizational commitment and job performance. The models have achieved a higher explanatory power, accounting for $75.5 \%$ from the variance of organizational commitment, and $45.3 \%$ from the variance of job performance. The main reason for this phenomenon is that for organizational commitment, 
emotions are the dominant force to influence it. Family-friendly human resource practice provides a supportive and trustful atmosphere, thus employees feel more respected and cared for by the organization. So, family-friendly human resource practice not only acts directly on organizational commitment, but also influences workplace spirituality. Likewise, one of the dimensions of job performance: contextual performance is also influenced by emotions.

The research has the following practical implications: First, to focus on employees' work-family relationship, and develop various family-friendly human resource plans. Organizations should strive to build a family-friendly organizational culture, and take measures, such as providing flexible working hours, telecommuting, paid leave, reimbursement of medical expenses, and care for the elderly and children of employees, In order to enhance employees' sense of self-identification and community, the implementation of family-friendly human resource measures can evoke gratefulness from employees and in turn benefits the organization. Second, to pay attention to compliments and combined utilization of internal charity and family-friendly human resource practice. Internal charity is designed for the organization's members and based on the interests of the employees. Hence, organizations should carefully adopt all kinds of policies for employees to support the balance the relationship between family and work. By doing this, employees will feel the altruistic atmosphere of organization, and overall result in better synergy between family and work. Third, to strengthen the construction of organization culture and create a more responsible and caring community culture. Finally, to meet employees' deep spiritual needs of personal ideals and contribution to others, improve employees' workplace spirituality, and stimulate their organizational commitment. This will ultimately improve the organization's overall performance.

\section{Limitations and Directions for Future Research}

Although this study has made some progress, but due to both objective and subjective factors, this study also has some shortcomings, and needs further research. First of all, geographical distribution of the sample is still not wide enough. The sample of this study is regional, mainly concentrated in Beijing. In order to improve the representativeness of the study, researchers can conduct a study in other regions. Second, more longitudinal and multilevel researches should be taken. Since the study is based on cross-sectional data, there is a certain degree of disadvantage. If researchers can conduct a longitudinal study, the internal validity of the study will be improved. Finally, in-depth studies about moderating variables should be taken, especially the moderate effects factors as leadership style, employee perception and finance level have on the relationship between family-friendly human resource practice and employees' attitude or behavior.

\section{Acknowledgements}

This paper is supported by National Natural Science Foundation of China 
(NSFC) "A research on the mechanism of corporate philanthropy's influences on the employees' attitudes and behaviors based on the workplace spirituality"

(No. 71102020).

\section{References}

[1] Mesmer-Magnus, J.R. and Viswesvaran, C. (2006) How Family-Friendly Work Environments Affect Work/Family Conflict: A Meta-Analytic Examination. Journal of Labor Research, 27, 555-574. https://doi.org/10.1007/s12122-006-1020-1

[2] Davis, A.E. and Kalleberg, A.L. (2006) Family-Friendly Organizations Work and Family Programs in the 1990s. Work and Occupations, 33, 191-223.

https://doi.org/10.1177/0730888405280446

[3] Aryee, S. (1992) Antecedents and Outcomes of Work-Family Conflict among Married Professional Women: Evidence from Singapore. Human Relations, 45, 813-837. https://doi.org/10.1177/001872679204500804

[4] Michael, L. and Durup, M. (1996) Work, Home, and In-Between: A Longitudinal Study of Spillover. Journal of Applied Behavioral Science, 32, 29-47.

https://doi.org/10.1177/0021886396321002

[5] Jeff, B. and Rashida, S. (2007) Family-Friendly Human Resource Practices and Organizational Commitment. Management Dynamics, 16, 2-10.

[6] Allen, N.J. and Meyer, J.P. (1996) Affective, Continuance, and Normative Commitment to the Organization: An Examination of Construct Validity. Journal of Vocational Behavior, 49, 252-276. https://doi.org/10.1006/jvbe.1996.0043

[7] Rotundo, M. and Sackett, P.R. (2002) The Relative Importance of Task, Citizenship, and Counterproductive Performance to Global Aspects of Job Performance: A Policy-Capturing Approach. Journal of Applied Psychology, 87, 66-80. https://doi.org/10.1037/0021-9010.87.1.66

[8] Ashmos, D.P. and Duchon, D. (2000) Spirituality at Work: A Conceptualization and Measure. Journal of Management Inquiry, 9, 134-145.

https://doi.org/10.1177/105649260092008

[9] Milliman, J., Czaplewski, A.J. and Jeffery, F. (2003) Workplace Spirituality and Employee Work Attitudes: An Exploratory Empirical Assessment. Journal of Organizational Change Management, 16, 426-447. https://doi.org/10.1108/09534810310484172

[10] Riasudeen, S. and Prabavathy, R. (2011) Relationship of Workplace Spirituality and Work Attitude in Manufacturing Organization. Global Management Review, 5, 29-37.

[11] Rego, A. and Cunha, M.P. (2008) Workplace Spirituality and Organizational Commitment: An Empirical Study. Journal of Organizational Change Management, 21, 53-75. https://doi.org/10.1108/09534810810847039

[12] Rastgar, A., Zarei, A., Davoudi, S.M. and Fartash, K. (2012) The Link between Workplace Spirituality, Organizational Citizenship Behavior and Job Performance in Iran. A Journal of Economics and Management, 6, 51-67.

[13] Glass, J. and Finley, A. (2002) Coverage and Effectiveness of Family-Responsive Workplace Policies. Human Resource Management Review, 12, 313-337. https://doi.org/10.1016/S1053-4822(02)00063-3

[14] Wise, S. and Bond, S. (2003) Work-Life Policy: Does It Do Exactly What It Says on the Tin? Women in Management Review, 18, 20-31.

https://doi.org/10.1108/09649420310462307 
[15] Hammer, L.B., Neal, M.B., Newsom, J.T., Brockwood, K.J. and Colton, C.L. (2005) A Longitudinal Study of the Effects of Dual-Earner Couples' Utilization of Family-Friendly Workplace Supports on Work and Family Outcomes. Journal of Applied Psychology, 90, 799-810. https://doi.org/10.1037/0021-9010.90.4.799

[16] Farkas, A.J. and Tetrick, L.E. (1989) A Three-Wave Longitudinal Analysis of the Causal Ordering of Satisfaction and Commitment on Turnover Decisions. Journal of Applied Psychology, 74, 855-868. https://doi.org/10.1037/0021-9010.74.6.855

[17] Springer, G.J. (2011) A Study of Job Motivation, Satisfaction, and Performance among Bank Employees. Journal of Global Business Issues, 5, 29-42.

[18] Ngo, H.Y., Foley, S. and Loi, R. (2009) Family Friendly Work Practices, Organizational Climate and Firm Performance: A Study of Multinational Corporations in Hong Kong. Journal of Organizational Behavior, 30, 665-680. https://doi.org/10.1002/job.606

[19] Joyce, W. and Slocum, J. (1984) Collective Climate: Agreement as a Basis for Defining Aggregate Climates in Organizations. Academy of Management Journal, 27, 721-742. https://doi.org/10.2307/255875

[20] Duchon, D. and Plowman, D.A. (2005) Nurturing Spirit at Work: Impact on Work Unit Performance. The Leadership Quarterly, 16, 807-833. https://doi.org/10.1016/j.leaqua.2005.07.008

[21] Platow, M.M., Wenzel, M. and Nolan, M. (2003) The Importance of Social Identity and Self-Categorization Processes for Creating and Responding to Fairness. In: Haslam, S.A., van Knippenberg, D., Platow, M.J. and Ellemers, N., Eds., Social Identity at Work, Psychology Press, New York, 261-276.

[22] Minna, L. (2008) Effects of Family Friendly Programs and Work-Family Culture: A Work-Family Enrichment Based Study. Zhejiang University, Hangzhou. (In Chinese)

[23] Meyer, J.P. and Allen, N.J. (1998) Commitment in the Work-Place: Theory, Research and Application. Journal of Academic Librarianship, 24, 175. https://doi.org/10.1016/S0099-1333(98)90184-7

[24] Williams, L.J. and Anderson, S.E. (1991) Job Satisfaction and Organizational Commitments as Predictors of Organizational Citizenship and in Role Behaviors. Journal of Management, 17, 601-617. https://doi.org/10.1177/014920639101700305

[25] Casper, W.J. and Buffardi, L.C. (2004) Work-Life Benefits and Job Pursuit Intentions: The Role of Anticipated Organizational Support. Journal of Vocational Behavior, 65, 391-410. https://doi.org/10.1016/j.jvb.2003.09.003

[26] Lobel, S.A. (1999) Impacts of Diversity and Work-Life Initiatives in Organizations. Handbook of Gender and Work, 453-476.

https://doi.org/10.4135/9781452231365.n23 